\title{
Article \\ A Robust Superhydrophobic Polyurethane Sponge Loaded with Multi-Walled Carbon Nanotubes for Efficient and Selective Oil-Water Separation
}

\author{
De Liu ${ }^{1}$, Shiying Wang ${ }^{2}$, Tao $\mathrm{Wu}^{2, *}$ and Yujiang $\mathrm{Li}^{1, *}$ \\ 1 Shandong Provincial Research Center for Water Pollution Control, School of Environmental Science and \\ Engineering, Shandong University, Qingdao 266237, China; 201912689@mail.sdu.edu.cn \\ 2 Key Laboratory of Colloid and Interface Science of Education Ministry, Shandong University, \\ Jinan 250100, China; 201912688@mail.sdu.edu.cn \\ * Correspondence: wutao@sdu.edu.cn (T.W.); yujiang@sdu.edu.cn (Y.L.); Tel./Fax: +86-531-88365437 (T.W.); \\ +86-531-88363358 (Y.L.)
}

Citation: Liu, D.; Wang, S.; Wu, T.; Li, Y. A Robust Superhydrophobic Polyurethane Sponge Loaded with Multi-Walled Carbon Nanotubes for Efficient and Selective Oil-Water Separation. Nanomaterials 2021, 11, 3344. https://doi.org/10.3390/nano 11123344

Academic Editor: George Z. Kyzas

Received: 16 November 2021

Accepted: 7 December 2021

Published: 9 December 2021

Publisher's Note: MDPI stays neutral with regard to jurisdictional claims in published maps and institutional affiliations.

Copyright: (c) 2021 by the authors. Licensee MDPI, Basel, Switzerland. This article is an open access article distributed under the terms and conditions of the Creative Commons Attribution (CC BY) license (https:// creativecommons.org/licenses/by/ $4.0 /)$.

\begin{abstract}
The influence of different coupling agents and coupling times on the wettability of a polyurethane (PU) sponge surface were optimized. Octadecyltrichlorosilane (OTS) was selected as the optimal coupling agent to prepare the superhydrophobic sponge. The superhydrophobic sponge was prepared in one step, which has the advantages of simple operation and enhanced durability. The superhydrophobic sponge was characterized by scanning electron microscopy, Teclis Tracker tensiometry, and Fourier transform infrared (FT-IR) spectrophotometry. The water contact angle increased from $64.1^{\circ}$ to $151.3^{\circ}$, exhibiting ideal superhydrophobicity. Oils and organic solvents with different viscosities and densities can be rapidly and selectively absorbed by superhydrophobic sponges, with an absorption capacity of 14.99 to 86.53 times the weight of the sponge itself, without absorbing any water. Since temperature affects the viscosity and ionic strength of oil, and influences the surface wettability of the sponges, the effect of temperature and ionic strength on the oil absorption capacity of the superhydrophobic sponges was measured, and its mechanism was elucidated. The results showed that the absorptive capacity retained more than $90 \%$ of the initial absorptive capacity after repeated use for 10 times. Low-cost, durable superhydrophobic sponges show great potential for large-scale oil-water separation.
\end{abstract}

Keywords: superhydrophobic; PU sponge; wettability; oil-water separation; multi-walled carbon nanotubes

\section{Introduction}

With the economic growth, the development of the petroleum industry and marine transportation have made marine oil spills a frequent and severe environmental challenge [1,2]. The spilled oil will eventually be consumed by humans after accumulating in farmed fish and shellfish, posing a major risk to human health, as well as to the aquatic environment [3,4]. Therefore, effective oil-water separation is urgently necessary. Various methods have been used for remediating oil spills, such as surface skimming [5-7], in situ burning [8] dispersants [9], and absorption. Due to its simple operation and easy separation, the absorption method is usually used for oil-water separations. Traditional absorbent substances such as cellulose [10,11], activated carbon [12,13] and zeolites [14], are mostly microporous materials. These materials therefore have a very low adsorption capacity, resulting in unsatisfactory oil-water separation efficiency. Therefore, researchers have attempted to find inexpensive and effective oil-water separation materials. 3D adsorbent materials possess the characteristics of large pores and large specific surface area, which can absorb oil on the material surface and realize oil-water separations [15]. In addition, they are not only inexpensive, but also have a large absorption capacity [16]. However, since 3D adsorbent materials' surface wettability is typically hydrophilic, they 
have an unsatisfactory hydrophobic oil absorption performance. Specifically, their oil absorption efficiency and oil-water separation efficiency are usually sub-optimal [17]. As a consequence, researchers have been searching for materials with a hydrophobic surface or a superhydrophobic surface, and a good affinity for hydrophobic oil droplets, for efficient oil-water separation.

A material with a water contact angle greater than $150^{\circ}$ is termed a superhydrophobic material [18-20]. Superhydrophobic materials can be obtained by simultaneously increasing the ruggedness of the material surface and reducing the surface free energy [21]. Three-dimensional porous materials with superhydrophobic/superlipophilic properties have received widespread attention because they can selectively absorb oil [22]. For example, polyurethane sponge is a 3D porous material that possesses excellent characteristics, such as low density, low price, superior elasticity, and high absorption capacity [23]. However, since sponges have hydroxyl and carboxyl groups on their surfaces, which are usually hydrophilic, surface modification is required [24]. For example, Qiu et al. [25] used one-step ultrasonic dip-coating method to obtain a superhydrophobic sponge. This sponge can selectively absorb a variety of oils and nonpolar solvents. Wu et al. [16] fabricated a superhydrophobic POS@HNT-PUF by the grafting of Hexadecyltrimethoxysilane (HDTMS) and Tetraethyl orthosilicate (TEOS), which can be used for oil-spill cleanup. In addition, some other nanomaterials, such as $\mathrm{SiO}_{2}$ nanoparticles [26], $\mathrm{Fe}_{3} \mathrm{O}_{4}$ nanoparticles [27,28], nanodiamonds [29] and reduced graphene oxide [23,30,31] have also been used to modify sponges. Multi-walled carbon nanotubes (MWCNTs) are used in various applications due to their outstanding electrical, optical, and mechanical properties [32,33]. In addition, MWCNTs can be used as an adsorbent material due to their high aspect ratio, low density, and good environmental chemical stability [34]. Hydroxylated multi-walled carbon nanotubes (MWCNTs-OH) are chemically functionalized materials with hydroxyl groups on their surface, making them easy to chemically modify $[35,36]$. However, since pure MWCNTs are one-dimensional solid materials with no oil storage space, they cannot be used directly for oil absorption.

In this paper, three kinds of hydrophobic long-chain siloxanes were selected to modify both carbon nanotubes and sponges, and the hydrophobic sponges were obtained by a onestep method. The hydrophobic sponge was characterized by Fourier transform infrared (FT-IR) spectrophotometry, scanning electron microscope, and interface rheometer. The effects of temperature and ionic strength on oil absorption efficiency of superhydrophobic sponges were also investigated. Several oils and organic solvents were adopted as model pollutants, and the absorption mechanism was identified and discussed.

\section{Experimental Section}

\subsection{Materials}

About $50 \mu \mathrm{m}$ long hydroxyl multi-walled carbon nanotubes (95\%), with an outer diameter of 8-15 $\mathrm{nm}$ and inner diameter of 3-5 nm were procured from Xfnano Materials Tech Co., Ltd. (Nanjing, China). Octadecyltrichlorosilane (OTS) with purity of $98 \%$ was procured from the Shanghai McLean Chemical Reagent Co., Ltd. (Shanghai, China). Polyurethane (PU) sponges were acquired from Top Daily Chemicals Co., Ltd. (Wuxi, China). Octadecyldimethyltrimethoxysilylpropylammonium chloride solution $\left(\mathrm{C}_{26} \mathrm{H}_{58} \mathrm{ClNO}_{3} \mathrm{Si}\right.$, 60 wt. \% in methanol) and hexadecyltrimethoxysilane $\left(\mathrm{H}_{3} \mathrm{C}\left(\mathrm{CH}_{2}\right)_{15} \mathrm{Si}\left(\mathrm{OCH}_{3}\right)_{3}, \geq 85 \%\right)$ were from Aladdin Reagents Co., Ltd. (Shanghai, China). Sulfuric acid $\left(\mathrm{H}_{2} \mathrm{SO}_{4}, 98.0 \%\right)$ was acquired from Laiyang Kan gde Chemical Co., Ltd. (Laiyang, China). Hydrogen peroxide (70\%) was acquired from Sinopharm Chemical Reagent Co., Ltd. (Shanghai, China). Various chemical reagents, including acetone, toluene, anhydrous ethanol, $\mathrm{CCl}_{4}$, and $\mathrm{NaCl}$, etc., were all of analytical grade.

\subsection{Pretreatment of Original PU Sponge}

After ultrasonic cleaning of PU sponge with acetone, absolute ethanol, and distilled water for $20 \mathrm{~min}$, respectively, it was put in a drying oven at $80{ }^{\circ} \mathrm{C}$ for $24 \mathrm{~h}$. Then the 
cleaned sponge was oxidized with $\mathrm{H}_{2} \mathrm{O}_{2} / \mathrm{H}_{2} \mathrm{SO}_{4}$ solution to make its surface rich in hydroxyl groups, which was easy to modify later. $70 \% \mathrm{H}_{2} \mathrm{O}_{2}$ was mixed with $\mathrm{H}_{2} \mathrm{SO}_{4}$ solution of $49 \%$ concentration in a volume ratio of 7:3. The washed PU sponge was soaked in the $\mathrm{H}_{2} \mathrm{O}_{2} / \mathrm{H}_{2} \mathrm{SO}_{4}$ solution for $4 \mathrm{~h}$, and then it was cleaned with distilled water. The pre-treated sponges were put in a vacuum drying oven at $80^{\circ} \mathrm{C}$ for $24 \mathrm{~h}$.

\subsection{Preparation of Coupling Agent-CNTs/PU Sponges}

Fifty mg of hydroxylated MWCNTs were slowly added to $50 \mathrm{~mL}$ of toluene, and the carbon nanotubes were dispersed by ultrasonication for $20 \mathrm{~min}$. Subsequently, the coupling agent was slowly added to prepare a liquid with a concentration of $0.05 \mathrm{~mol} / \mathrm{L}$. The pre-treated PU sponge was immersed in the modified CNTs/toluene solution, and the compound was magnetically agitated at $300 \mathrm{rpm}$ for $24 \mathrm{~h}$. The mixed system was ultrasonicated for $20 \mathrm{~min}$, and then allowed to stand for $2 \mathrm{~h}$. Eventually, the coupling agent-CNTs/PU sponge was removed, then was placed in a drying oven and dried at $80^{\circ} \mathrm{C}$ for $24 \mathrm{~h}$.

\subsection{Characterization}

The static water contact angle (WCA) was observed on a Teclis Tracker tensiometer (Teclis Instruments, Civrieux d'Azergues, France). Scanning electron microscopy (SEM) images of sponges were acquired on a JSM-6330F scanning electron microscope (JEOL Ltd., Tokyo, Japan). The $\zeta$-potential of the sponges was assessed by a SurPASS analyzer (Anton Paar, Graz, Austria). Fourier transform infrared (FT-IR) spectrophotometry of the pristine and modified PU sponges were obtained on an AXS FT-IR spectrophotometer (Bruker, Karlsruhe, Germany), with $\mathrm{KBr}$ used as the dispersion medium. The viscosity of the oil at different temperatures was measured by a HAAKE RS75 Rheometer (Thermo Fisher Scientific, Waltham, MA, USA). Thermogravimetric analysis (TGA) curves were recorded using a TGA5500 system (TA Instruments Co. Ltd., New Castle, DE, USA) under a nitrogen atmosphere by heating from 20 to $500{ }^{\circ} \mathrm{C}$ at a heating rate of $10^{\circ} \mathrm{C} / \mathrm{min}$.

\subsection{Oil Absorption of the OTS-CNTs/PU Sponge to Different Oils}

The absorption capacity of OTS-CNTs/PU sponge on soybean oil, kerosene, chloroform, petroleum ether, hexadecane, and crude oil was tested. The oil absorption test conditions of the sponge were as follows: the sponge was soaked in oil for $5 \mathrm{~min}$, and then taken out and weighed. The following formula was used to calculate the absorption capacity:

$$
k=\frac{m_{p}-m_{o}}{m_{o}}
$$

where $m_{p}$ and $m_{s}$ are the mass of OTS-CNTs/PU sponges prior to and after adsorption, separately. The results of each group were measured three times and averaged.

\section{Result and Discussion}

\subsection{Preparation of Superhydrophobic Sponge \\ 3.1.1. Selection of Coupling Agents}

Octadecyldimethyltrimethoxysilylpropylammonium chloride, hexadecyltrimethoxysilane and octadecyltrichlorosilane (OTS) were selected as coupling agents, which fully reacted with the hydroxyl groups on the carbon nanotubes and PU sponges under the condition of magnetic stirring for $24 \mathrm{~h}$. The coupling agent was grafted on the surfaces of the hydroxylated multi-walled carbon nanotubes and PU sponges. Then, the carbon nanotubes were loaded on the PU sponge by the ultrasonic method. The FTIR spectra of various coupling agent-CNTs/PU sponges are displayed in Figure 1 . The peak at $3430 \mathrm{~cm}^{-1}$ in the pre-treated PU sponge spectrum was ascribed to the stretching vibration peak of the $-\mathrm{OH}$ group [22]. The bands at $1110 \mathrm{~cm}^{-1}$ were assigned to the $\mathrm{C}-\mathrm{O}$ stretching vibration [18]. The adsorption band at $1656 \mathrm{~cm}^{-1}$ corresponded to the presence of the $\mathrm{C}=\mathrm{C}$ bonds [37]. The adsorption bands at $615 \mathrm{~cm}^{-1}$ were ascribed to $-\mathrm{SO}_{3} \mathrm{H}$. After modification, the FT-IR 
spectrum of the coupling agent-CNTs/PU sponge exhibited certain changes. For instance, the FT-IR spectrum of the OTS-CNTs/PU sponges showed four additional absorption peaks at $2923,2849,1470$ and $719 \mathrm{~cm}^{-1}$, corresponding to the stretching vibration and bending vibration of the long-chain alkyl methylene $\mathrm{C}-\mathrm{H}$ [38]. Additionally, the adsorption band at 1112 and $1057 \mathrm{~cm}^{-1}$ were ascribed to $\mathrm{Si}-\mathrm{O}-\mathrm{Si}$ and $\mathrm{Si}-\mathrm{O}-\mathrm{C}$, respectively $[37,39]$. The FT-IR spectra of other coupling agent-CNTs/PU sponges had similar peaks, indicating that the hydroxyl groups reacted with the coupling agents.

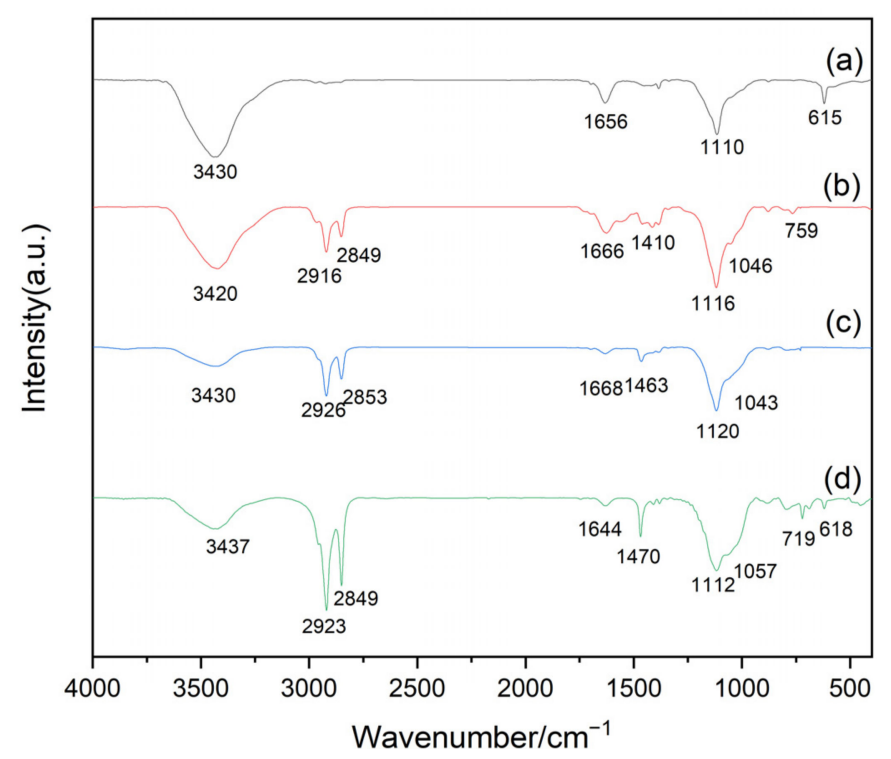

Figure 1. Fourier transform infrared (FT-IR) spectrophotometry of: (a) pre-treated polyurethane (PU) sponge, (b) octadecyldimethyltrimethoxy-carbon nanotubes (CNTs)/PU sponge, (c) hexadecyltrimethoxylsilane-CNTs/PU sponge, and (d) octadecyltrichlorosilane (OTS)-CNTs/PU sponge.

Wettability is a solid-liquid interface property [21]. The wettability was judged by performing water contact angle tests on three modified sponges [40]. It can be seen from Figure 2a that the WCAs of the pre-treated PU sponges are $64.1 \pm 1.2^{\circ}$, which is hydrophilic. The hydrophilicity of the pre-treated sponge is ascribed to the hydroxyl on the surface. The WCAs of the prepared sponges were also measured, and the modified sponges give WCAs of $93.2 \pm 1.1^{\circ}, 134.9 \pm 1.0^{\circ}$, and $151.3 \pm 1.2^{\circ}$ for octadecyldimethyltrimethoxysilylpropylammonium chloride-CNTs/PU sponge, hexadecyltrimethoxysilane-CNTs/PU sponge, and octadecyltrichlorosilane (OTS)-CNTs/PU sponge (OTS-CNTs/PU sponge), respectively, which means that the modified sponges are harder to be wet with water (Figure 2b-d). Among them, OTS-CNTs/PU has the largest WCAs, which is higher than $150^{\circ}$, completely repels the water, and thus exhibits markedly ideal superhydrophobicity.

To study the superficial morphology of the pre-treated PU sponges and the modified PU sponges, scanning electron microscope (SEM) tests were performed. Low magnification images of the pre-treated PU sponges and modified sponges are presented in Figure 3A. The pristine PU sponges have a unique 3D layered porous structure, with a pore size between 200-500 microns, and the large pore structure of the sponge gives it more space to store oil. Extant literature has demonstrated that nanomaterials with low surface free energy are easy to uniformly adhere to the sponge skeleton without destroying its inherent structure $[26,41]$. As shown in Figure $3 \mathrm{~A}(\mathrm{c}, \mathrm{d})$, the OTS-CNTs/PU sponge and hexadecyltrimethoxysilane-CNTs/PU sponge maintained the original 3D porous structure, indicating that its absorption capacity did not decrease. However, the skeleton structure of the octadecyldimethyltrimethoxysilylpropylammonium chloride-CNTs/PU sponge was damaged to a certain extent. 

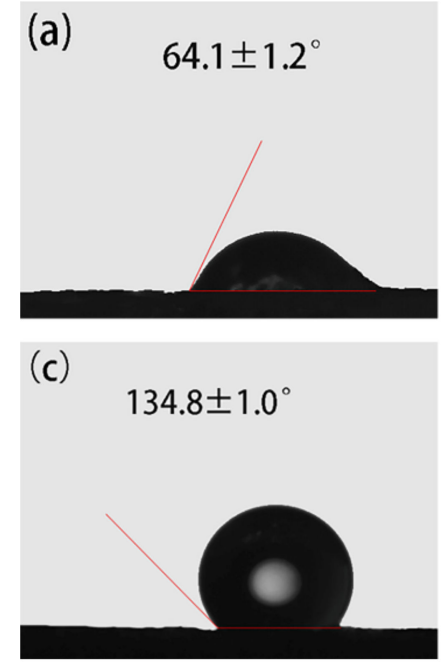

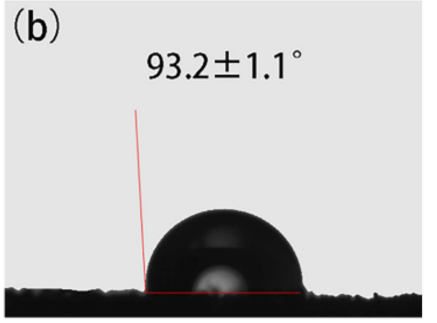

(d)

Figure 2. Water contact angles (WCAs) of various coupling agent-CNTs/PU sponges: (a) pre-treated PU sponge, (b) octadecyldimethyltrimethoxysilylpropylammonium chloride-CNTs/PU sponge, (c) hexadecyltrimethoxysilane-CNTs/PU sponge, and (d) Octadecyltrichlorosilane (OTS)-CNTs/PU sponge (experimental conditions: $\mathrm{pH}=7$, coupling time $=24 \mathrm{~h}$ at $25^{\circ} \mathrm{C}$ ).
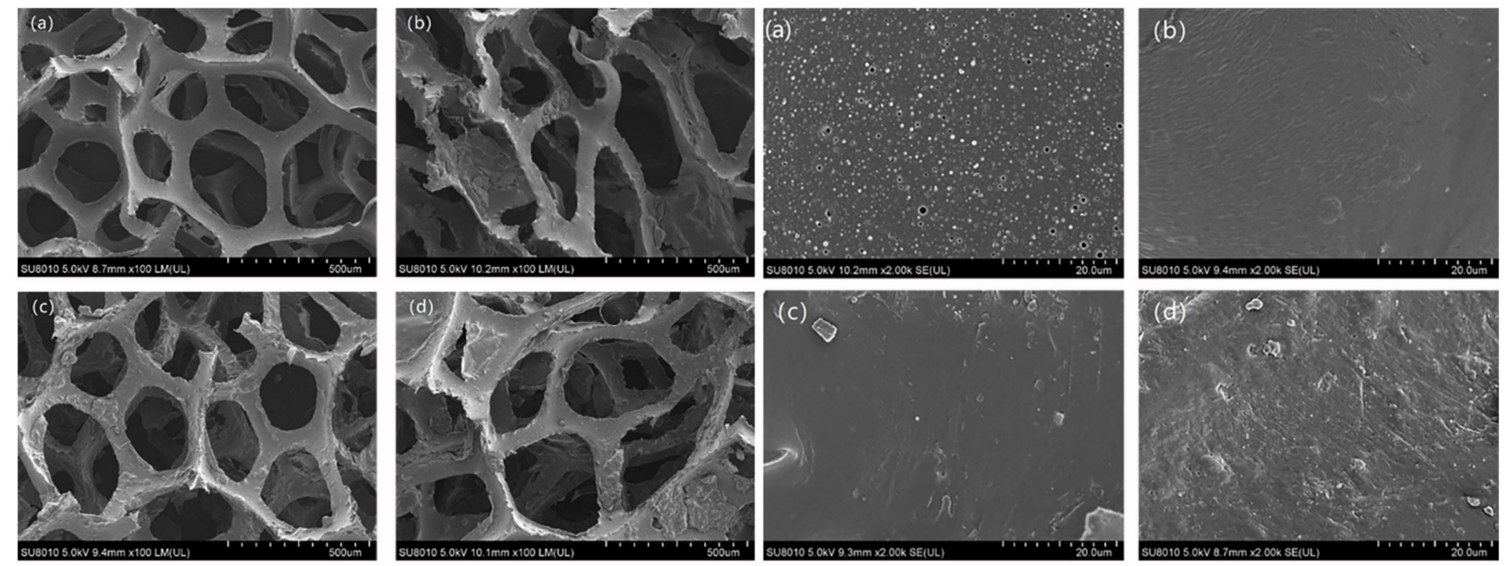

(A)

(B)

Figure 3. Low magnification (A) and high magnification (B) Scanning electron microscopy (SEM) images of (a) pretreated sponge, (b) octadecyldimethyltrimethoxysilylpropylammonium chloride-CNTs/PU, (c) hexadecyltrimethoxylsilaneCNTs/PU, and (d) OTS-CNTs/PU with coupling time $=24 \mathrm{~h}$.

Figure 3B provides higher magnification images. As shown in Figure 3B, there is a small number of carbon nanotubes on the octadecyldimethyltrimethoxysilylpropylammonium chloride-CNTs/PU sponges, while there are more carbon nanotubes on the hexadecyltrimethoxylsilane-CNTs/PU sponges and OTS-CNTs/PU sponges. Among them, the OTS-CNTs/PU sponge has a rougher surface and stronger hydrophobicity. In addition, longer alkyl chains lead to greater hydrophobicity [42]. Therefore, octadecyltrichlorosilane was selected as the coupling agent.

\subsubsection{Selection of Coupling Time}

The sponges loaded with carbon nanotubes with a coupling time of $6 \mathrm{~h}, 12 \mathrm{~h}, 24 \mathrm{~h}$, and $48 \mathrm{~h}$ were selected for FT-IR analysis. As indicated in Figure 4, the intensity of the peaks of $\mathrm{Si}-\mathrm{O}-\mathrm{Si}$ and $\mathrm{CH}_{2}$ increased with coupling time. 


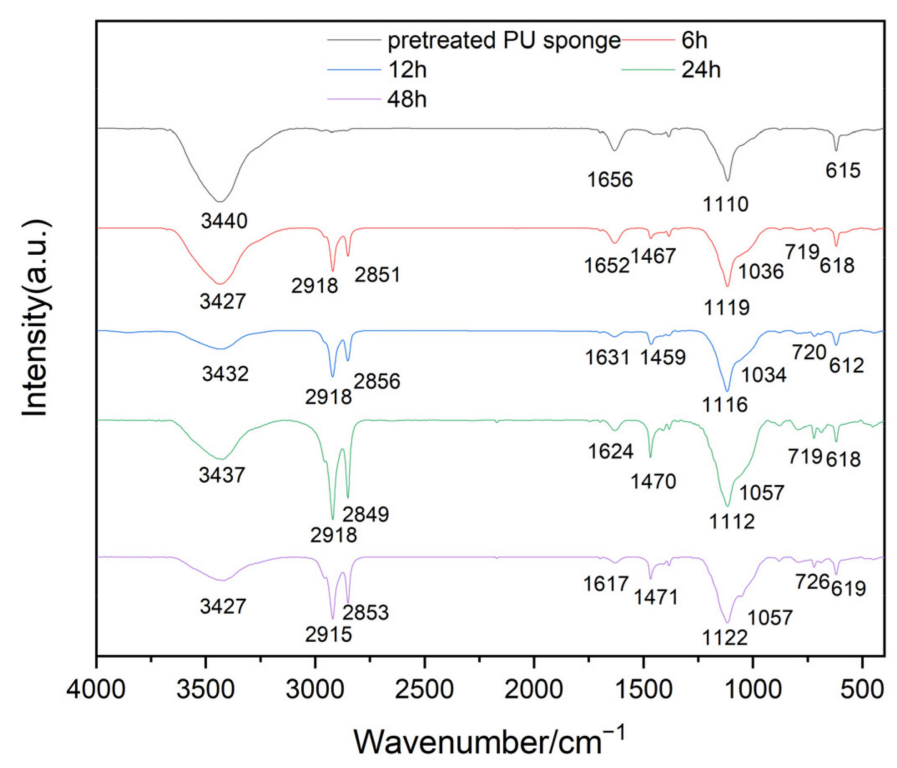

Figure 4. FT-IR spectra of OTS-CNTs/PU sponge with different coupling times.

As indicated in Figure 5, wettability was measured by water contact angle test. As the coupling time increased, the water contact angle increased, indicating that its hydrophobicity increased. This is because the longer is the coupling time, the fuller is the reaction between carbon nanotubes and OTS. When the coupling time was $24 \mathrm{~h}$, the water contact angle was $151.3 \pm 1.2^{\circ}$, which is superhydrophobic. When the coupling time changed from $24 \mathrm{~h}$ to $48 \mathrm{~h}$, the water contact angle did not change significantly, indicating that the carbon nanotubes and OTS had reacted completely.

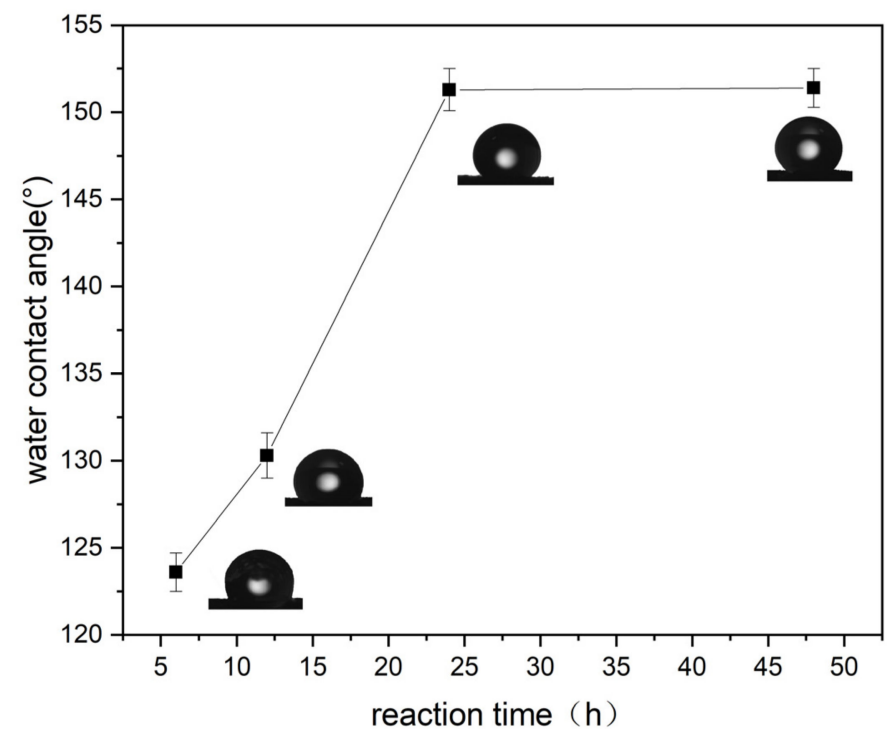

Figure 5. Effect of coupling time on the WCA (experimental conditions: $\mathrm{pH}=7$, coupling time $=24 \mathrm{~h}$ at $\left.25^{\circ} \mathrm{C}\right)$.

Figure 6 presents SEM diagrams of different coupling times. As the coupling time increased, the number of carbon nanotubes loaded on the sponge surfaces increased, thus increasing the surface ruggedness. The increase in surface roughness facilitated the enhancement of hydrophobicity. Therefore, considering both the wettability and the adsorption capacity of the sponge, the OTS-CNTs/PU sponge with a coupling time of $24 \mathrm{~h}$ was selected. 

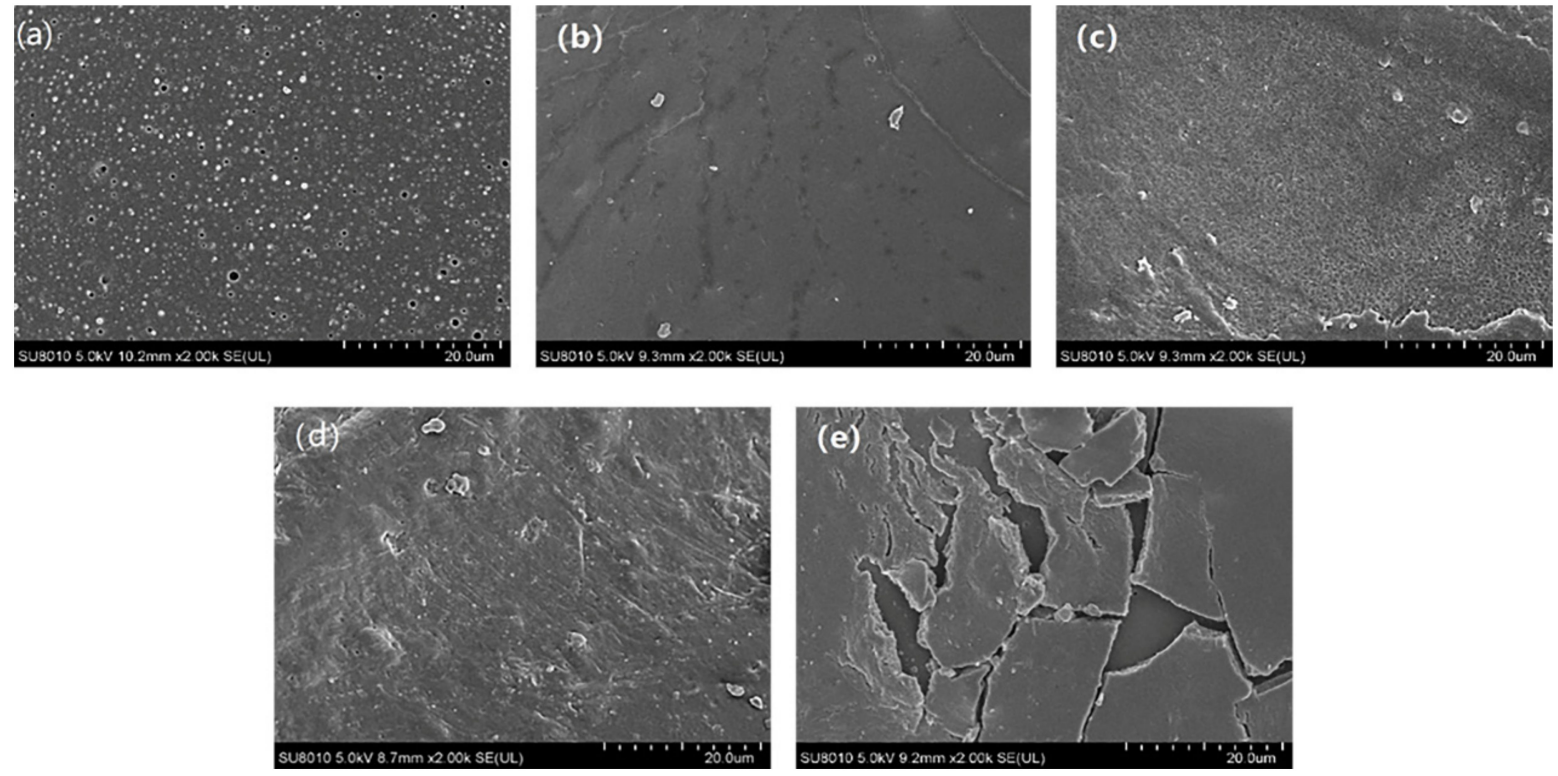

Figure 6. High magnification SEM images of OTS-CNTs/PU with different coupling times (a) pre-treated sponge, (b) $6 \mathrm{~h}$, (c) $12 \mathrm{~h},(\mathbf{d}) 24 \mathrm{~h}$, and (e) $48 \mathrm{~h}$.

\subsection{Oil Absorption Test}

\subsubsection{Oil-Water Separation Process}

The OTS-CNTs/PU sponge could float when placed on water surface (Figure 7a). As indicated in Figure 7b, as the superhydrophobic sponge was dipped in water with forceps, a silvery, mirror-like film of air formed around its surface, which shows that the sponge possessed the surface characteristics of Cassie Baxter [43]. Because of this air film, the superhydrophobic sponge cannot be infiltrated by water. When the tweezers were removed, the superhydrophobic sponge promptly floated onto the water surface and did not increase in weight, indicating that it had not absorbed water.
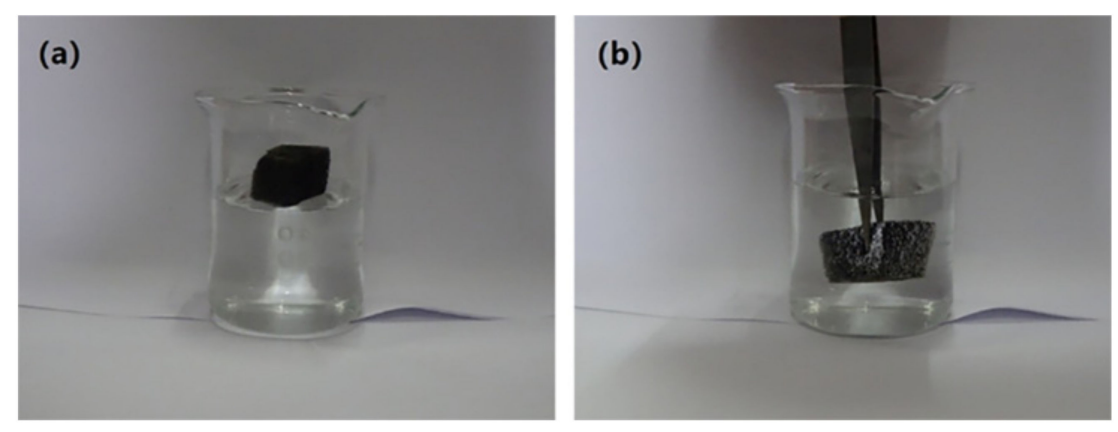

Figure 7. (a) Optical image of OTS-CNTs/PU sponge floating on the water surface; (b) optical image of OTS-CNTs/PU sponge immersed in a water bath under external force.

In this study, hexadecane and chloroform were adopted for the absorption process observation experiment. As indicated in Figure 8a, oil-red stained hexadecane was added on water, and then the OTS-CNTs/PU sponge was dipped on the immiscible oil-water mixture. In seconds, the oil was completely absorbed by the OTS-CNTs/PU sponge. When the sponge was clamped away with a tweezer, a clear and transparent water surface was obtained. Figure $8 \mathrm{~b}$ shows the sponge absorbing chloroform (dyed with oil red) from underwater. Immersion of OTS-CNTs/PU sponge into water can form a three-phase sponge-air-water interface. The super-hydrophobicity of the sponge kept water out of the sponge. When chloroform was in proximity to the superhydrophobic sponge, it was 
promptly absorbed into the sponge. The oil-water selective separation process was finally completed in a short period of time.
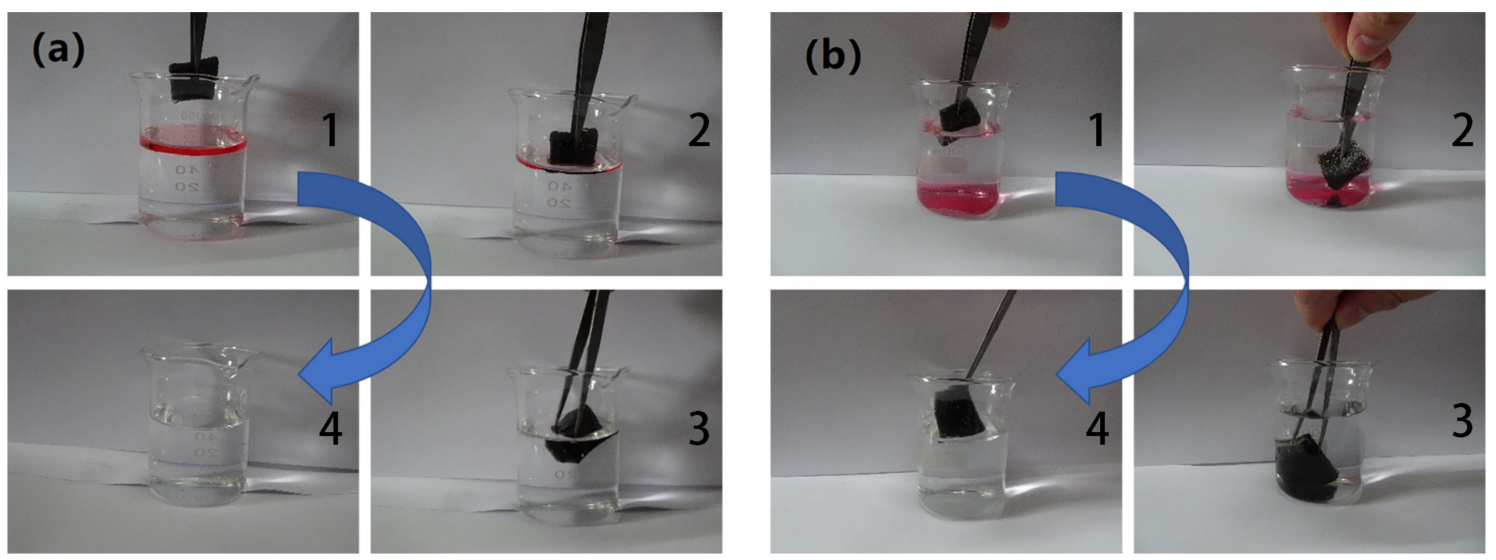

Figure 8. (a) Optical images of the removal process of hexadecane from the water surface using OTS-CNTs/PU sponge; (b) optical images of the removal process of chloroform from underwater using OTS-CNTs/PU sponge (The blue arrow shows the sequence $1-4$ of oil absorption process).

\subsubsection{Impact of Environmental Factors on the Efficiency of Oil-Water Separation}

Since oil and organic solvent spills usually occur under complex environmental conditions, it is crucial to elucidate the performance of superhydrophobic sponges under various conditions $[44,45]$. The oil absorption efficiency of superhydrophobic sponges can be affected by changes in environmental factors. For example, temperature can influence the viscosity of the oil, and ionic strength can affect the apparent wettability of the superhydrophobic sponges, thereby affecting the oil absorption efficiencies of the superhydrophobic sponges.

\section{Effect of Density and Viscosity}

When oil is absorbed in the pores of the superhydrophobic sponge by capillary force, it fills the volume of the pores. Under the action of the hydrophobic force, the hydrophobic oil will also be adsorbed on the outer surface of the sponges. As seen in Table 1, the absorption capacities of the six different oils vary from 14.99 times to 86.53 times, which is attributable to the different viscosity, density, and other properties of the oils [46]. The amount of oil that can be stored per unit volume of the sponge composite increases as the density of the oil increases. At the same time, for high viscosity oil, the high viscosity prevents it from diffusing into the internal pores of the adsorbent, resulting in ineffective oil capture [47]. The oil absorption capacity of the sponge increases after modification (Table 2), which is related to its enhanced hydrophobicity.

Table 1. Absorption capacity of the Octadecyltrichlorosilane (OTS)-carbon nanotubes (CNTs)/ polyurethane (PU) sponges for various organic oils and solvents $\left(20^{\circ} \mathrm{C}\right)$.

\begin{tabular}{cccc}
\hline Samples & Density $(\mathbf{g} / \mathbf{m L})$ & Viscosity $(\mathbf{m P a s})$ & Absorption Capacity $(\mathbf{g} / \mathbf{g})$ \\
\hline Soybean oil & 0.919 & 76.59 & 14.99 \\
Kerosene & 0.79 & 3.489 & 36.78 \\
Petroleum ether & 0.705 & 1.75 & 26.91 \\
Chloroform & 1.484 & 1.726 & 86.53 \\
Crude oil & 0.835 & 6.087 & 36.81 \\
Hexadecane & 0.773 & 7.645 & 31.65 \\
\hline
\end{tabular}


Table 2. Absorption capacity of $\mathrm{t}$ different PU sponges for various organic oils and solvents $\left(20^{\circ} \mathrm{C}\right)$.

\begin{tabular}{ccccccc}
\hline $\begin{array}{c}\text { Absorption } \\
\text { Capacity (g/g) }\end{array}$ & $\begin{array}{c}\text { Soybean } \\
\text { Oil }\end{array}$ & Kerosene & $\begin{array}{c}\text { Petroleum } \\
\text { Ether }\end{array}$ & Chloroform & $\begin{array}{c}\text { Crude } \\
\text { Oil }\end{array}$ & Hexadecane \\
\hline $\begin{array}{c}\text { OTS- } \\
\text { CNTs/PU } \\
\text { sponge }\end{array}$ & 14.99 & 36.78 & 26.91 & 86.53 & 36.81 & 31.65 \\
$\begin{array}{c}\text { OTS-PU } \\
\text { sponge }\end{array}$ & 14.81 & 36.60 & 26.82 & 86.39 & 35.66 & 31.57 \\
$\begin{array}{c}\text { Pre-treated PU } \\
\text { sponge }\end{array}$ & 14.17 & 35.66 & 26.15 & 85.37 & 32.68 & 30.89 \\
\hline
\end{tabular}

\section{Effect of Temperature}

Increasing the oil temperature can reduce the oil viscosity $[48,49]$, which can make the oil more fluid [50]. Temperature can alter the oil viscosity and fluidity, thereby affecting the oil absorption efficiency of the superhydrophobic sponges.

Chloroform, crude oil, and kerosene were used to determine the influence of temperature on the oil absorption of superhydrophobic sponges. As presented in Table 3, the oil absorption of sponges at $20,40,60$ and $80{ }^{\circ} \mathrm{C}$ were measured, and the oil viscosity at different temperatures when the shear rate was $1 \mathrm{~s}^{-1}$ was measured. As the temperature increased, the viscosity of various oils decreased. For high viscosity oils, the reduced viscosity causes the oil to be more easily absorbed by the sponge. But for the lower viscosity oil, the lower viscosity causes its adhesion on the sponge skeleton to decrease.

Table 3. Effect of temperature on oil absorption capacity (shear rate was fixed as $1 \mathrm{~s}^{-1}$ to measure viscosity of the oil).

\begin{tabular}{cccc}
\hline Samples & Temperature $\left({ }^{\circ} \mathbf{C}\right)$ & Viscosity $(\mathbf{m P a s})$ & Absorption Capacity $(\mathrm{g} / \mathrm{g})$ \\
\hline Chloroform & 20 & 3.177 & 86.53 \\
& 40 & 3.063 & 85.76 \\
& 60 & 2.941 & 85.62 \\
Crude oil & 80 & $*$ & 36.81 \\
& 20 & 11.78 & 37.26 \\
& 40 & 9.276 & 37.91 \\
Kerosene & 60 & 7.413 & 38.68 \\
& 80 & 6.087 & 36.79 \\
& 20 & 3.489 & 35.92 \\
& 40 & 2.764 & 35.02 \\
\hline
\end{tabular}

* Chloroform boils at $80^{\circ} \mathrm{C}$.

Effect of Ionic Strength

Surface wettability of superhydrophobic sponges can be affected by ionic strength, which in turn influences the oil absorption capacity. The ionic strength can be changed by adding electrolytes (e.g., $\mathrm{NaCl}$ and $\mathrm{CaCl}_{2}$ ). The OTS-CNTs/PU sponges were soaked in different concentrations of $\mathrm{NaCl}$ or $\mathrm{CaCl}_{2}$ solution for $24 \mathrm{~h}$, and their WCAs were measured after drying. Subsequently, their absorption of different oils was assessed. It can be seen from Table 4 that as the ionic strength increased, the WCA of the OTS-CNTs/PU sponge decreased, indicating that the hydrophobicity decreased. Moreover, the oil absorption of the sponge composite material will also decrease. This is because the wettability of the sponge changed from superhydrophobic to hydrophobic, resulting in a reduction in the hydrophobic force between the sponge and the oil droplets. The effects of the two salts on the sponge composites were also compared, and it was found that the same concentration of $\mathrm{CaCl}_{2}$ had a greater impact on the hydrophobicity and oil absorption of OTS-CNTs/PU sponges than did $\mathrm{NaCl}$. The zeta potential of the superhydrophobic sponge is $-20.78 \mathrm{mV}$. $\mathrm{Ca}^{2+}$ and $\mathrm{Na}^{+}$can be adsorbed to the surface of the sponge through electrostatic action, 
and they are easily combined with water molecules in the air and liquid phase through hydrogen bonds, resulting in the reduction of water contact angle and the change of surface wettability from superhydrophobic to hydrophobic, which in turn affects the absorption efficiency. The interaction between $\mathrm{Ca}^{2+}$ and water molecules is greater than the interaction between $\mathrm{Na}^{+}$and water molecules.

Table 4. Effect of ionic strength on oil absorption capacity $\left(20^{\circ} \mathrm{C}\right)$.

\begin{tabular}{ccccccc}
\hline Samples & $\mathbf{c}(\mathbf{N a C l})$ & WCA & Absorption $\mathbf{( g / g )}$ & $\mathbf{c}\left(\mathbf{C a C l}_{\mathbf{2}}\right)$ & WCA & Absorption $(\mathrm{g} / \mathrm{g})$ \\
\hline Chloroform & 0 & $151.3^{\circ}$ & 86.53 & 0 & $151.3^{\circ}$ & 86.53 \\
& 0.002 & $143.1^{\circ}$ & 86.39 & 0.002 & $142.8^{\circ}$ & 85.88 \\
& 0.004 & $141.6^{\circ}$ & 86.12 & 0.004 & $140.5^{\circ}$ & 85.59 \\
& 0.006 & $134.4^{\circ}$ & 85.76 & 0.006 & $132.6^{\circ}$ & 85.15 \\
Crude oil & 0.008 & $125.2^{\circ}$ & 85.12 & 0.008 & $120.9^{\circ}$ & 85.11 \\
& 0 & $151.3^{\circ}$ & 36.81 & 0 & $151.3^{\circ}$ & 36.81 \\
& 0.002 & $143.1^{\circ}$ & 36.17 & 0.002 & $142.8^{\circ}$ & 35.94 \\
& 0.004 & $141.6^{\circ}$ & 36.10 & 0.004 & $140.5^{\circ}$ & 35.74 \\
Kerosene & 0.006 & $134.4^{\circ}$ & 36.08 & 0.006 & $132.6^{\circ}$ & 35.60 \\
& 0.008 & $125.2^{\circ}$ & 35.77 & 0.008 & $120.9^{\circ}$ & 35.58 \\
& 0 & $151.3^{\circ}$ & 36.79 & 0 & $151.3^{\circ}$ & 36.79 \\
& 0.002 & $143.1^{\circ}$ & 36.68 & 0.002 & $142.8^{\circ}$ & 36.63 \\
& 0.004 & $141.6^{\circ}$ & 36.64 & 0.004 & $140.5^{\circ}$ & 36.4 \\
& 0.006 & $134.4^{\circ}$ & 36.51 & 0.006 & $132.6^{\circ}$ & 36.07 \\
\hline
\end{tabular}

WCA: water contact angle.

\subsection{Reusability of the Superhydrophobic Sponge}

Due to the grafting of OTS with MWCNTs, the weight of the modified sponge was increased by about $33 \%$. CNTs possess unique mechanical toughness [51]. Therefore, when a $200 \mathrm{~g}$ weight was placed on a $20 \mathrm{~mm} \times 20 \mathrm{~mm} \times 20 \mathrm{~mm}$ pristine PU sponge and superhydrophobic sponge, the PU sponge was severely squashed and deformed, whereas, the OTS-CNTs/PU sponge could remain undeformed due to its excellent mechanical strength (Figure 9). This shows that the OTS-CNTs/PU sponge has unique mechanical strength. The enhancement of mechanical strength is ascribed to the mechanical enhancement of carbon nanotubes loaded on the skeleton of the sponges [18]. The thermal stability of pre-treated sponges and OTS-CNTs/PU sponges was investigated by TGA curves [52,53]. As shown in Figure $9 \mathrm{~b}$, the pre-treated sponge decomposed almost completely at $350-450{ }^{\circ} \mathrm{C}$, and the residual weight of $3.5 \%$ at $500{ }^{\circ} \mathrm{C}$. In contrast, the residual weight of OTS-CNTs/PU sponge at $500{ }^{\circ} \mathrm{C}$ was $54.65 \%$, indicating its improved heat resistance after modification.

(a)

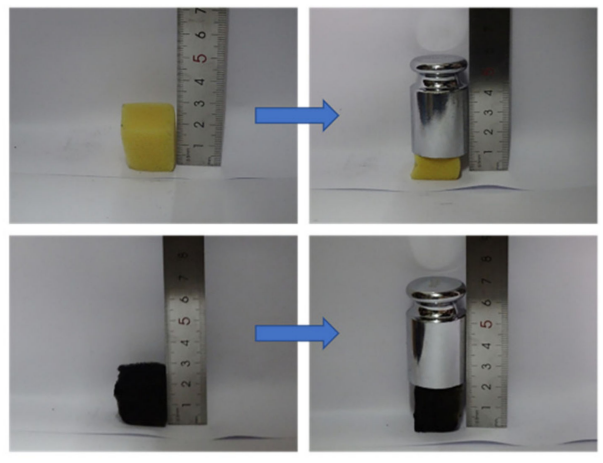

(b)

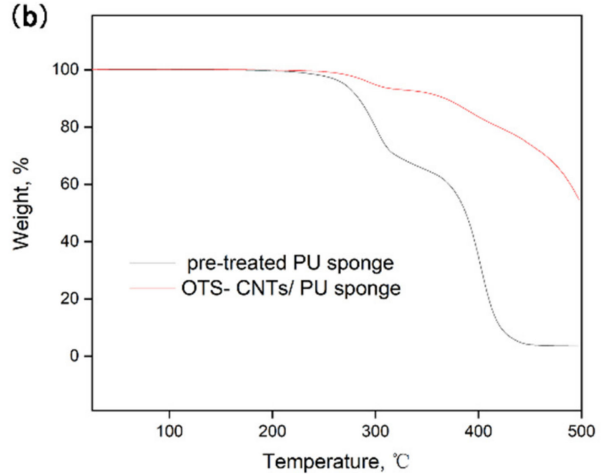

Figure 9. (a) Shape of PU sponge and OTS-CNTs/PU sponge under the same external force; (b) Thermogravimetric analysis (TGA) curves of pre-treated PU sponge and OTS-CNTs/PU sponge.

The adsorption performance of OTS-CNTs/PU sponges was examined by performing 10 replicate adsorption/desorptions of six kinds of oils. As seen in Figure 10, the oil 
absorption ability of OTS-CNTs/PU sponges decreased slightly during 10 cycles. This is because the recycling of the sponge composite material is realized through the mechanical extrusion process. However, the oil absorbed by the material cannot be completely squeezed out during the mechanical extrusion process, and the oil will remain in the pores of the sponge, thus increasing its weight [54]. Furthermore, the extrusion process will cause irreversible deformation of OTS-CNTs/PU sponges, which will reduce the oil storage space of the sponge. Several reported oil-absorbing materials were compared (Table 5) and OTS-CNTs/PU sponges showed good performance.
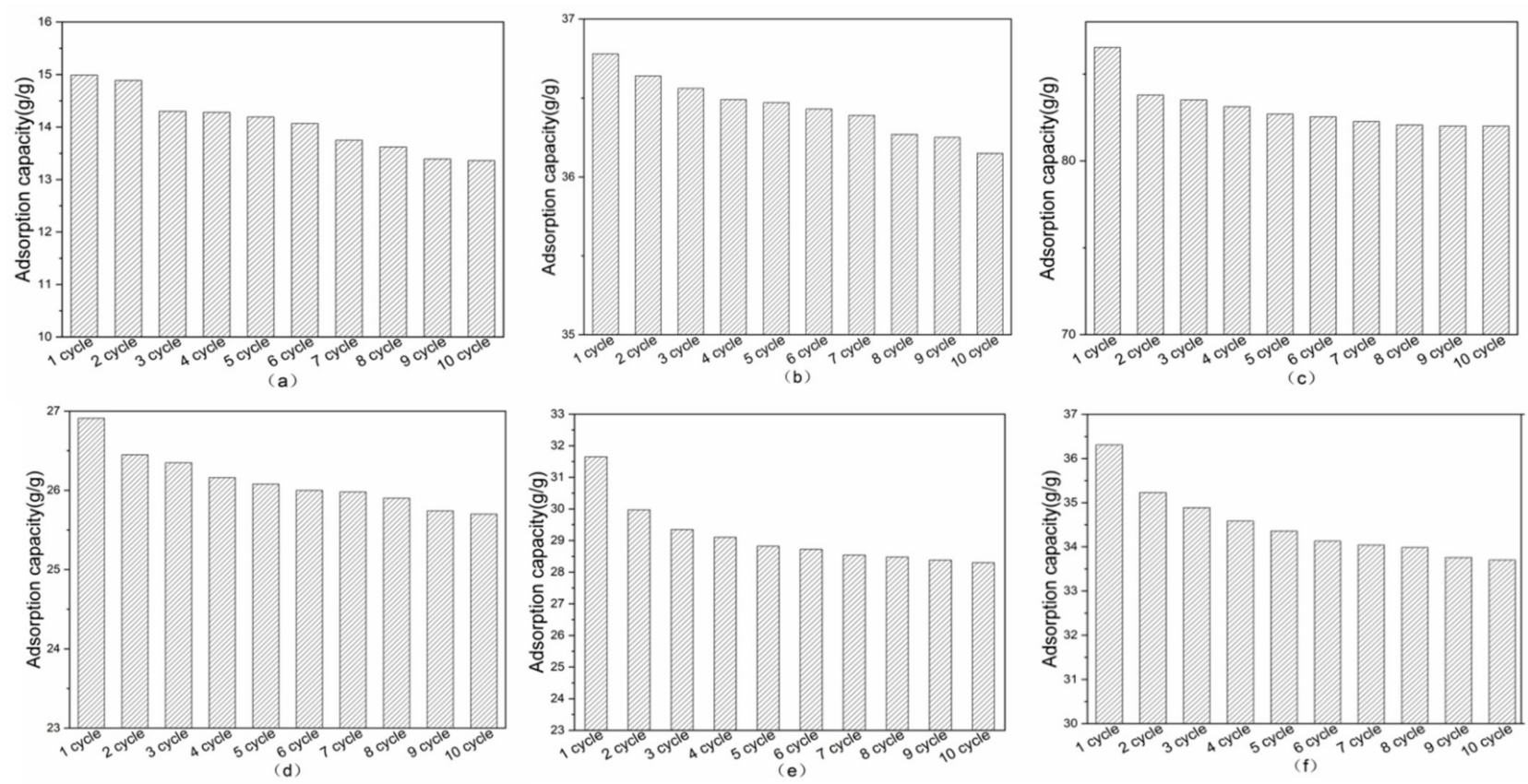

Figure 10. Variations in absorption capacities of OTS-CNTs/PU sponge for various oils under 10 cycles: (a) soybean oil; (b) kerosene; (c) chloroform; (d) petroleum ether; (e) hexadecane; and (f) crude oil.

Table 5. WCA and oil absorption capacity of different absorbent materials.

\begin{tabular}{ccccc}
\hline Adsorption Material & WCA & Sorbate & Oil Adsorption Capacity (g/g) & Reference \\
\hline Cellulosic materials & $148^{\circ}$ & diesel oil & 33 & {$[55]$} \\
PU-PNIPAAm & $135^{\circ}$ & 1,2-dibromoethane & 11.31 & {$[37]$} \\
N-CNS & $142^{\circ}$ & ethylene glycol & 30 & {$[50,56]$} \\
CNTs/PUF & $131^{\circ}$ & chloroform & 33.04 & {$[57]$} \\
PU-NDs-fPDA sponge & $>150^{\circ}$ & chloroform & 74.32 & {$[29]$} \\
CSTN & $150^{\circ}$ & chloroform & 80.28 & {$[58]$} \\
RGO/OAP/PU & $>150^{\circ}$ & chloroform & 20.97 & {$[23]$} \\
PUf-g-LMA & $*$ & kerosene & 27.7 & {$[59]$} \\
NCPUF & $148^{\circ}$ & kerosene & 36.78 & [60] \\
OTS-CNTs/PU sponge & $150.2^{\circ}$ & kerosene & 86.53 & Present work \\
OTS-CNTs/PU sponge & $150.2^{\circ}$ & chloroform & Present work \\
\hline
\end{tabular}

* Not mentioned in the reference.

\section{Conclusions}

In this study, different coupling agents and coupling times were selected to prepare superhydrophobic sponges. Finally, octadecyltrichlorosilane was used as the optimal coupling agent to prepare the optimum superhydrophobic sponge. The introduction of long-chain alkyl groups makes the sponge superhydrophobic and increases the water contact angle from $64.1^{\circ}$ to $151.3^{\circ}$. The superhydrophobic sponge is prepared by a onestep method, so that OTS can react not only with hydroxyl groups on CNTs, but also with hydroxyl groups on pretreated sponges, making the prepared sponges more durable. 
Six oils with different viscosities and densities were selected as model pollutants for the absorption capacity test. The superhydrophobic sponge possesses excellent mechanical properties and large absorption capacity, which can absorb oil that is 14.99 to 86.53 times its own weight. In addition, it can be reused 10 times by squeezing, and its absorption capacity does not decrease significantly. The influence of temperature and ionic strength on it was also measured, and it was found that the absorption of oil by the superhydrophobic sponge is based on capillary force and hydrophobic force. Therefore, the OTS-CNTs/PU sponge constitutes a highly potential candidate for oil spill absorption.

Author Contributions: Conceptualization, T.W. and Y.L.; methodology, T.W.; software, D.L.; validation, D.L.; formal analysis; investigation, Y.L.; resources, Y.L.; data curation, D.L. and S.W.; writing-original draft preparation, T.W.; writing-review and editing, T.W.; visualization, D.L.; supervision, Y.L.; project administration, Y.L.; funding acquisition, Y.L. All authors have read and agreed to the published version of the manuscript.

Funding: This work is supported by the National Natural Science Foundation of China (Grant No. 21677087), and the National Science and Technology Major Project of China (Grant No. 2016ZX05040-005).

Data Availability Statement: Data can be available upon request from the authors.

Acknowledgments: The authors express gratitude to Jake Carpenter from UCLA for linguistic consultation.

Conflicts of Interest: The authors declare no conflict of interest.

\section{References}

1. Dhumal, P.S.; Khose, R.V.; Wadekar, P.H.; Lokhande, K.D.; Some, S. Graphene-bentonite supported free-standing, flexible membrane with switchable wettability for selective oil-water separation. Sep. Purif. Technol. 2021, 266, 118569. [CrossRef]

2. Kulal, D.K.; Khose, R.V.; Pethsangave, D.A.; Wadekar, P.H.; Some, S. Biomass-derived lignocellulosic graphene composite: Novel approach for removal of oil and organic solvent. ChemistrySelect 2019, 4, 4568-4574. [CrossRef]

3. Carpenter, A. Oil pollution in the North Sea: The impact of governance measures on oil pollution over several decades. Hydrobiologia 2019, 845, 109-127. [CrossRef]

4. Jamaly, S.; Giwa, A.; Hasan, S.W. Recent improvements in oily wastewater treatment: Progress, challenges, and future opportunities. J. Environ. Sci. 2015, 37, 15-30. [CrossRef]

5. Al-Majed, A.A.; Adebayo, A.R.; Hossain, M.E. A sustainable approach to controlling oil spills. J. Environ. Manag. 2012, 113, 213-227. [CrossRef]

6. Broje, V.; Keller, A.A. Improved mechanical oil spill recovery using an optimized geometry for the skimmer surface. Environ. Sci. Technol. 2006, 40, 7914-7918. [CrossRef]

7. Broje, V.; Keller, A.A. Effect of operational parameters on the recovery rate of an oleophilic drum skimmer. J. Hazard. Mater. 2007, 148, 136-143. [CrossRef]

8. Aurell, J.; Gullett, B.K. Aerostat sampling of PCDD/PCDF emissions from the gulf oil spillin situ burns. Environ. Sci. Technol. 2010, 44, 9431-9437. [CrossRef]

9. Kujawinski, E.B.; Soule, M.C.K.; Valentine, D.L.; Boysen, A.K.; Longnecker, K.; Redmond, M.C. Fate of dispersants associated with the deepwater horizon oil spill. Environ. Sci. Technol. 2011, 45, 1298-1306. [CrossRef]

10. Paul, U.C.; Fragouli, D.; Bayer, I.S.; Athanassiou, A. Functionalized cellulose networks for efficient oil removal from oil-water emulsions. Polymers 2016, 8, 52. [CrossRef]

11. Liu, H.; Geng, B.; Chen, Y.; Wang, H. Review on the aerogel-type oil sorbents derived from nanocellulose. ACS Sustain. Chem. Eng. 2017, 5, 49-66. [CrossRef]

12. Xu, J.L.; Xu, Y.; Liang, L.; Wang, J.; Luo, L.X. Removal of COD from heavy oil wastewater by activated carbon. In Advanced Materials Research; Trans Tech Publications Ltd.: Zurich, Germany, 2012; pp. 2325-2328.

13. Ahmad, A.L.; Sumathi, S.; Hameed, B.H. Residual oil and suspended solid removal using natural adsorbents chitosan, bentonite and activated carbon: A comparative study. Chem. Eng. J. 2005, 108, 179-185. [CrossRef]

14. Shavandi, A.; Haddadian, Z.; Ismail, M.H.S.; Abdullah, N.; Abidin, Z.Z. Removal of residual oils from palm oil mill effluent by adsorption on natural zeolite. Water Air Soil Pollut. 2012, 223, 4017-4027. [CrossRef]

15. Ma, Q.; Cheng, H.; Fane, A.G.; Wang, R.; Zhang, H. Recent development of advanced materials with special wettability for selective oil/water separation. Small 2016, 12, 2186-2202. [CrossRef]

16. Wu, F.; Pickett, K.; Panchal, A.; Liu, M.; Lvov, Y.M. Superhydrophobic polyurethane foam coated with polysiloxane-modified clay nanotubes for efficient and recyclable oil absorption. ACS Appl. Mater. Interfaces 2019, 11, 25445-25456. [CrossRef] 
17. Zhou, X.; Zhang, Z.; Xu, X.; Men, X.; Zhu, X. Facile fabrication of superhydrophobic sponge with selective absorption and collection of oil from water. Ind. Eng. Chem. Res. 2013, 52, 9411-9416. [CrossRef]

18. Wang, H.; Wang, E.; Liu, Z.; Gao, D.; Yuan, R.; Sun, L.; Zhu, Y. A novel carbon nanotubes reinforced superhydrophobic and superoleophilic polyurethane sponge for selective oil-water separation through a chemical fabrication. J. Mater. Chem. A 2014, 3, 266-273. [CrossRef]

19. Gao, J.; Hao, M.; Wu, T.; Li, Y. Efficient treatment of crude oil-contaminated hydrodesulphurization catalyst by using surfactant/solvent mixture. J. Environ. Chem. Eng. 2021, 9, 105890. [CrossRef]

20. Ahmed, R.M.; Anis, B.; Khalil, A.S. Facile surface treatment and decoration of graphene-based 3D polymeric sponges for high performance separation of heavy oil-in-water emulsions. J. Environ. Chem. Eng. 2021, 9, 105087. [CrossRef]

21. Xue, Z.; Cao, Y.; Liu, N.; Feng, L.; Jiang, L. Special wettable materials for oil/water separation. J. Mater. Chem. A 2014, 2, 2445-2460. [CrossRef]

22. Chen, X.-Q.; Zhang, B.; Xie, L.; Wang, F. MWCNTs polyurethane sponges with enhanced super-hydrophobicity for selective oil-water separation. Surf. Eng. 2020, 36, 651-659. [CrossRef]

23. Jamsaz, A.; Goharshadi, E.K. Flame retardant, superhydrophobic, and superoleophilic reduced graphene oxide/orthoaminophenol polyurethane sponge for efficient oil/water separation. J. Mol. Liq. 2020, 307, 112979. [CrossRef]

24. Liu, Y.; Ma, J.; Wu, T.; Wang, X.; Huang, G.; Qiu, H.; Li, Y.; Wang, W.; Gao, J. Cost-effective reduced graphene oxide-coated polyurethane sponge as a highly efficient and reusable oil-absorbent. ACS Appl. Mater. Interfaces 2013, 5, 10018-10026. [CrossRef]

25. Qiu, S.; Li, Y.; Li, G.; Zhang, Z.; Li, Y.; Wu, T. Robust superhydrophobic sepiolite-coated polyurethane sponge for highly efficient and recyclable oil absorption. ACS Sustain. Chem. Eng. 2019, 7, 5560-5567. [CrossRef]

26. Lin, B.; Chen, J.; Li, Z.-T.; He, F.-A.; Li, D.-H. Superhydrophobic modification of polyurethane sponge for the oil-water separation. Surf. Coat. Technol. 2018, 359, 216-226. [CrossRef]

27. Zhu, Q.; Pan, Q. Mussel-inspired direct immobilization of nanoparticles and application for oil-water separation. ACS Nano 2014, 8, 1402-1409. [CrossRef]

28. Liang, L.; Liu, P.; Su, H.; Qian, H.; Ma, H. One-step fabrication of superhydrophobic sponge with magnetic controllable and flame-retardancy for oil removing and collecting. J. Appl. Polym. Sci. 2020, 137, e4935344. [CrossRef]

29. Cao, N.; Yang, B.; Barras, A.; Szunerits, S.; Boukherroub, R. Polyurethane sponge functionalized with superhydrophobic nanodiamond particles for efficient oil/water separation. Chem. Eng. J. 2017, 307, 319-325. [CrossRef]

30. Xia, C.; Li, Y.; Fei, T.; Gong, W. Facile one-pot synthesis of superhydrophobic reduced graphene oxide-coated polyurethane sponge at the presence of ethanol for oil-water separation. Chem. Eng. J. 2018, 345, 648-658. [CrossRef]

31. Tjandra, R.; Lui, G.; Veilleux, A.; Broughton, J.; Chiu, G.; Yu, A. Introduction of an enhanced binding of reduced graphene oxide to polyurethane sponge for oil absorption. Ind. Eng. Chem. Res. 2015, 54, 3657-3663. [CrossRef]

32. De Volder, M.F.L.; Tawfick, S.H.; Baughman, R.H.; Hart, A.J. Carbon nanotubes: Present and future commercial applications. Science 2013, 339, 535-539. [CrossRef] [PubMed]

33. Yan, Y.; Miao, J.; Yang, Z.; Xiao, F.-X.; Bin Yang, H.; Liu, B.; Yang, Y. Carbon nanotube catalysts: Recent advances in synthesis, characterization and applications. Chem. Soc. Rev. 2015, 44, 3295-3346. [CrossRef] [PubMed]

34. Parmar, K.R.; Dora, D.T.K.; Pant, K.; Roy, S. An ultra-light flexible aerogel-based on methane derived CNTs as a reinforcing agent in silica-CMC matrix for efficient oil adsorption. J. Hazard. Mater. 2019, 375, 206-215. [CrossRef] [PubMed]

35. Balasubramanian, K.; Burghard, M. Chemically functionalized carbon nanotubes. Small 2005, 1, 180-192. [CrossRef]

36. Bradley, R.H.; Cassity, K.; Andrews, R.; Meier, M.; Osbeck, S.; Andreu, A.; Johnston, C.; Crossley, A. Surface studies of hydroxylated multi-wall carbon nanotubes. Appl. Surf. Sci. 2012, 258, 4835-4843. [CrossRef]

37. Yi, P.; Hu, H.; Sui, W.; Zhang, H.; Lin, Y.; Li, G. Thermoresponsive polyurethane sponges with temperature-controlled superwettability for oil/water separation. ACS Appl. Polym. Mater. 2020, 2, 1764-1772. [CrossRef]

38. Ling, X.-L.; Wei, Y.-Z.; Zou, L.-M.; Xu, S. Preparation and characterization of hydroxylated multi-walled carbon nanotubes. Colloids Surf. A Physicochem. Eng. Asp. 2013, 421, 9-15. [CrossRef]

39. Lin, Y.; He, D.; Hu, H.; Yi, P.; Liu, X.; Huang, J.; Wu, S.; Li, G. Preparation and properties of polydimethylsiloxane (PDMS)/Polyethylene glycol (PEG)-based amphiphilic polyurethane elastomers. ACS Appl. Bio Mater. 2019, 2, $4377-4384$. [CrossRef]

40. Ahuja, D.; Dhiman, S.; Rattan, G.; Monga, S.; Singhal, S.; Kaushik, A. Superhydrophobic modification of cellulose sponge fabricated from discarded jute bags for oil water separation. J. Environ. Chem. Eng. 2021, 9, 105063. [CrossRef]

41. Li, M.; Bian, C.; Yang, G.; Qiang, X. Facile fabrication of water-based and non-fluorinated superhydrophobic sponge for efficient separation of immiscible oil/water mixture and water-in-oil emulsion. Chem. Eng. J. 2019, 368, 350-358. [CrossRef]

42. Li, Y.; Wang, M.; Sun, D.; Li, Y.; Wu, T. Effective removal of emulsified oil from oily wastewater using surfactant-modified sepiolite. Appl. Clay Sci. 2018, 157, 227-236. [CrossRef]

43. Cassie, A.B.D.; Baxter, S. Wettability of porous surfaces. Trans. Faraday Soc. 1944, 40, 546-551. [CrossRef]

44. Li, Y.; Zhang, Z.; Wang, M.; Men, X.; Xue, Q. One-pot fabrication of nanoporous polymer decorated materials: From oil-collecting devices to high-efficiency emulsion separation. J. Mater. Chem. A 2017, 5, 5077-5087. [CrossRef]

45. Li, J.; Xu, C.; Zhang, Y.; Wang, R.; Zha, F.; She, H. Robust superhydrophobic attapulgite coated polyurethane sponge for efficient immiscible oil/water mixture and emulsion separation. J. Mater. Chem. A 2016, 4, 15546-15553. [CrossRef] 
46. Yuan, D.; Zhang, T.; Guo, Q.; Qiu, F.; Yang, D.; Ou, Z. Recyclable biomass carbon@SiO $\mathrm{SnO}_{2}$ aerogel with hierarchical structures for fast and selective oil-water separation. Chem. Eng. J. 2018, 351, 622-630. [CrossRef]

47. Chang, J.; Shi, Y.; Wu, M.; Li, R.; Shi, L.; Jin, Y.; Qing, W.; Tang, C.; Wang, P. Solar-assisted fast cleanup of heavy oil spills using a photothermal sponge. J. Mater. Chem. A 2018, 6, 9192-9199. [CrossRef]

48. Luo, P.; Gu, Y. Effects of asphaltene content on the heavy oil viscosity at different temperatures. Fuel 2007, 86, 1069-1078. [CrossRef]

49. Alomair, O.; Jumaa, M.; Alkoriem, A.; Hamed, M. Heavy oil viscosity and density prediction at normal and elevated temperatures. J. Pet. Explor. Prod. Technol. 2016, 6, 253-263. [CrossRef]

50. Ge, J.; Shi, L.-A.; Wang, Y.-C.; Zhao, H.-Y.; Yao, H.-B.; Zhu, Y.-B.; Zhang, Y.; Zhu, H.-W.; Wu, H.-A.; Yu, S.-H. Joule-heated graphene-wrapped sponge enables fast clean-up of viscous crude-oil spill. Nat. Nanotechnol. 2017, 12, 434-440. [CrossRef]

51. Zapata-Solvas, E.; García, D.G.; Dominguez-Rodriguez, A. Towards physical properties tailoring of carbon nanotubes-reinforced ceramic matrix composites. J. Eur. Ceram. Soc. 2012, 32, 3001-3020. [CrossRef]

52. Pethsangave, D.A.; Wadekar, P.; Khose, R.V.; Some, S. Super-hydrophobic carrageenan cross-linked graphene sponge for recovery of oil and organic solvent from their water mixtures. Polym. Test. 2020, 90, 106743. [CrossRef]

53. Khose, R.V.; Wadekar, P.; Pethsangave, D.A.; Chakraborty, G.; Ray, A.K.; Some, S. Novel approach towards the synthesis of highly efficient flame retardant electrode and oil/organic solvent absorber. Chemosphere 2020, 246, 125785. [CrossRef]

54. Khosravi, M.; Azizian, S. Synthesis of a novel highly oleophilic and highly hydrophobic sponge for rapid oil spill cleanup. ACS Appl. Mater. Interfaces 2015, 7, 25326-25333. [CrossRef]

55. Łukawski, D.; Lisiecki, F.; Dudkowiak, A. Coating cellulosic materials with graphene for selective absorption of oils and organic solvents from water. Fibers Polym. 2018, 19, 524-530. [CrossRef]

56. Cortés-López, A.J.; Muñoz-Sandoval, E.; López-Urías, F. Efficient carbon nanotube sponges production boosted by acetone in CVD-Synthesis. Carbon 2018, 135, 145-156. [CrossRef]

57. Zhang, T.; Gu, B.; Qiu, F.; Peng, X.; Yue, X.; Yang, D. Preparation of carbon nanotubes/Polyurethane hybrids as a synergistic absorbent for efficient oil/water separation. Fibers Polym. 2018, 19, 2195-2202. [CrossRef]

58. Muñoz-Sandoval, E.; Cortés-López, A.J.; Flores-Gómez, B.; Fajardo-Diaz, J.L.; Sanchez-Salas, R.; López-Urías, F. Carbon spongetype nanostructures based on coaxial nitrogen-doped multiwalled carbon nanotubes grown by CVD using benzylamine as precursor. Carbon 2017, 115, 409-421. [CrossRef]

59. Li, H.; Liu, L.; Yang, F. Hydrophobic modification of polyurethane foam for oil spill cleanup. Mar. Pollut. Bull. 2012, 64, 1648-1653. [CrossRef]

60. Sabouri, M.R.; Javanbakht, V.; Ghotbabadi, D.J.; Mehravar, M. Oily wastewater treatment by a magnetic superoleophilic nanocomposite foam. Process. Saf. Environ. Prot. 2019, 126, 182-192. [CrossRef] 